\title{
DE HERMANOS Y UTOPÍAS, DIÁLOGO ENTRE ECUADOR Y MÉXICO (1928-1938)
}

Nuestra generación — días más, días menos, entre los siglos XIX y XX- tuvo su niñez y su adolescencia encandiladas, deslumbradas por la imagen de México. Méjico, como nos corregía el profesor de castellano. Pero México, con $\mathrm{X}$, una inmensa $\mathrm{X}$ para nosotros, que en ello encontrábamos fuerza y personalidad distinguidoras. Benjamín Carrión

México produce conscientemente la idea de un hermano mayor, más experimentado, que va triunfando en el arreglo de sus condiciones de vida y a quien queremos emular para poder vivir a su misma altura[...].

Pablo Palacio

RESUMEN: Este artículo muestra los vínculos entre la literatura y la historia de la cultura de Ecuador y México, entre los años veinte y treinta del siglo $X X$, a partir del rastreo de fuentes poco conocidas. En este ensayo, dividido entre "documentos históricos" y "textos literarios", la autora elabora algunas de las relaciones político-ideológicas de los escritores, que desempeñan un papel tanto en la literatura como en la política. En el ámbito político, la relación se instaura a partir de la imagen que los escritores ecuatorianos tienen en estos años sobre la Revolución mexicana. Se entrevé México como utopía fundamental en la relación con Latinoamérica. Como se trata de autores de la denominada vanguardia histórica, el ideal estético y el ideal político se superponen y confunden, en la misma noción de vanguardia.

* Centro de Estudios Literarios-Instituto de Investigaciones Filológicas, UNAM, (yanna@servidor.unam.mx). 
PAlabRas Clave: Literatura, Ecuador, México, Años veinte y treinta, Vanguardia.

ABSTRACT: This article shows the links between Mexico and Ecuador's literature and cultural history during the 1920's and 1930's. The information in it was obtained in non- explored sources. In this paper, which consists of two parts, historical documents and literary texts, the author displays some of the political and ideological bonds of a group of writers who played a major role both in literature and in politics. Regarding the latter, the bond emerges from how Ecuadorian authors imagine the Mexican revolution. Mexico was actually seen as a fundamental utopia for Latin America. As this paper deals with writers of the so-called historical avant- garde, the esthetical and political ideals melt into the same notion of vanguard.

KEYS WORDS: Literature, Ecuador, Mexico, The 20's and the 30's, Vanguard.

Las relaciones comentadas de la literatura ecuatoriana con la iberoamericana siguen siendo una tarea pendiente en los estudios literarios del Ecuador. Si bien es cierto que la crítica se ha perfilado hacia la confrontación con Latinoamérica en estos últimos años, sobre todo en torno a la figura de Pablo Palacio, en la época que nos ocupa, al parecer, el paso de las coincidencias históricas y bibliográficas hacia las similitudes estilísticas continúa en el tintero. Este artículo quiere resaltar algunas líneas posibles del diálogo político y estético entre discurso literario y discurso social entre México y Ecuador, a partir de ciertos señalamientos historiográficos y literarios.

\section{LOS DOCUMENTOS HISTÓRICOS}

\section{Una verdadera correspondencia}

El hallazgo del documento al que me referiré, hasta ahora inédito y desconocido, me permite afirmar que el contacto entre estridentistas y vanguardistas ecuatorianos fue más que una probabilidad entre contemporáneos. 
Carta de Pablo Palacio a Germán List Arzubide:

Pablo Palacio

Quito, Ecuador

(todo manuscrito)

Oct.2/928

A germán list arzubide

Compañero:

Una larga enfermedad me ha impedido agradecerle a tiempo por su carta acerca de "Débora", publicado en su Revista.

List Arzubide estoy francamente agradecido de Ud. Tal vez su nota ha sido la más comprensiva de mi obra, que se haya publicado en el continente. Desearía mantener correspondencia estrecha con Ud. y que no dejara de enviarme publicaciones de su país.

Oiga: estoy encantado con los mexicanos, de lo que hacen los mexicanos. Me parece que uds. deben ser bastante felices.

Hágame un favor: quiero que diga a Maples Arce que su libro "Poemas interdictos", es lindo. ¿Por qué no me manda Ud. los suyos? tengo solamente "El movimiento estridentista". Un apretón de manos por él, especialmente por la presentación de Arqueles Vela. ¿Qué hermosa es!

Reciba un saludo cordial de

Palacio*

Por los datos que se tienen de la bio-bibliografía del destinatario, se asume que Pablo Palacio, el narrador de vanguardia más importante de Ecuador, debe referirse al comentario de su novela Débora (publicada en Quito, en octubre de 1927) aparecido en Semáforo, publicación de Jalapa, Veracruz, que dirige List Arzubide entre 1927 y 1928 . Desafortunadamente, la misma no ha sido localizada. En todo caso, para cuando aparece en 1928 el folleto memoria que edita List Arzubide en Estridentópolis (Jalapa), Opiniones sobre el libro "El movimiento estridentista" ( sin editorial), en el que compila las respuestas internacionales a la publicación de su libro El movimiento estridentista (Horizonte, Jalapa, 1926), se consignan las cartas de varios otros lectores ecuatorianos en-

* Se conservó el formato de la carta original. 
viadas desde Quito (Humberto Salvador y Gregorio Cordero y León), Guayaquil (L.A. Lavayen Flores) y Cuenca (Vicente Moreno Mora); ${ }^{1}$ con lo cual se evidencia que Palacio no es el único ecuatoriano para entonces en contacto con el autor mexicano.

El positivo comentario de Palacio sobre los textos estridentistas tiene además un matiz de admiración que parece rebasar lo literario. Dice Palacio: "Oiga: estoy encantado con los mexicanos, de lo que hacen los mexicanos. Me parece que uds. deben ser bastante felices". Es oportuno recordar que en el México de los años veinte se inician las acciones de reforma en educación y cultura de los gobiernos revolucionarios en el poder, y que los estridentistas concilian muy pronto su insatisfacción con la cultura oficial pre-revolucionaria al volverse actores del cambio, trabajando, desde su personal voluntad renovadora e iconoclasta, al servicio del proyecto cultural nacionalista y revolucionario. ${ }^{2}$ Quizá desde este contexto resulte posible entender la alegría de la que habla Palacio: se trataría del gozo de la realización de lo que parecía utópico.

En las páginas de la revista Horizonte (1926-1927), que dirige List Arzubide, encontramos frecuentes menciones a obras del gobierno del Estado de Veracruz que rebasan lo estrictamente cultural: la Universidad de Jalapa, el estadio, los nuevos planes de educación, la publicación de colecciones de clásicos literarios para la divulgación. La publicación $\mathrm{Ho}$ rizonte, por ejemplo, es una tribuna del gobierno del general Heriberto Jara, gobernador de Veracruz, con quien colabora estrechamente Maples Arce. Frente a esto, resuenan seguramente más desoladores los artículos de la vanguardia ecuatoriana, que se ve a sí misma sin salida, concentra-

1 Entre otros latinoamericanos destacados (como Juana de Ibarbouru, Magda Portal, Alberto Hidalgo, Serafín Delmar); quienes a su vez también fueron incluidos en publicaciones ecuatorianas de la época como la guayaquileña Savia (1925-1928).

2 Cfr. Claude Fell, José Vasconcelos. Los años del águila (1920-1925). Educación, cultura e iberoamericanismo en el México postrevolucionario, México, UNAM, 1989. Para el mismo tema de la política cultural como motor de los estridentistas, véase Katharina Niemayer, "Arte-vida: ¿Ida y vuelta? El caso del estridentismo”, Naciendo el hombre nuevo...Fundir literatura, artes y vida como práctica de las vanguardias en el Mundo Ibérico, Frankfurt am Main, Vervuert/Iberoamericana, 1999, pp. 187-211. 
da en el paradigmático "aquí el artista es un perdido" de Raúl Andrade, publicado en la misma revista en que aparecen textos de Palacio para los mismos años, donde leemos el encierro y la incomprensión en que se encuentra la sensibilidad ecuatoriana de avanzada para entonces:

Si alguna vez se interroga a un muchacho de Quito, de mediano refinamiento espiritual, por el mayor deseo de su vida, surgirá invariablemente la respuesta, amarga y desconsoladora:

-Irme de aquí[...]

Querer irse, partir, perderse en las vorágines cosmopolitas, como aspiración máxima de una juventud prometedora, no se me negará que es doloroso. [...] El asunto es partir, no importa a donde. Y hay en ese perenne deseo de partir una oculta esperanza de presidiario o náufrago. ${ }^{3}$

Más allá del afortunado hallazgo de la carta, la frecuencia de contacto entre las vanguardias mexicana y ecuatoriana durante esos años es algo indudable. En la revista $\mathrm{Savia}^{4}$ de Guayaquil se anuncia a Hugo Mayo como "representante" del estridentismo en Ecuador, distribuidor de las publicaciones de los autores mexicanos: "Hugo Mayo ha distribuido en librerías 'Poemas interdictos', libro del camarada M. Maples Arce, edición lujosamente presentada por la Editorial Horizonte de Jalapa”. Palacio, colaborador de la revista guayaquileña Savia al igual que Mayo, ${ }^{5}$ habrá conocido, si no lo hizo antes, a los estridentistas a partir de esta publicación. Los textos que menciona en la carta corresponden justamente a los que se incluyen en el número 42 de Savia, como una

3 Hélice. Revista quincenal de arte, núm. 5, Quito, 27 de septiembre, 1926, p. 10. La revista es editada por el pintor Camilo Egas y el escritor Raúl Andrade.

4 Savia, núm. 39, Guayaquil, 4 de enero, 1928, p. 23, según mi conteo.

La publicación quincenal guayaquileña Savia, subtitulada Revista de Información, Arte i Letras, editada por Gerardo Gallegos y José Aspiazu Valdés, aparece por vez primera el $1^{\circ}$ de julio de 1925 . Pervivirá por más de tres años.

5 Hugo Mayo, seudónimo literario de Miguel Augusto Egas (1898-1988), a pesar de seguir poco estudiado por la crítica con alguna excepción, se considera el más radical de los poetas de vanguardia en Ecuador. Cfr. Jackelín Verdugo Cárdenas, Hugo Mayo y la vanguardia, Cuenca, Ecuador, Facultad de Filosofía, Letras y Ciencias de la Educación de la Universidad de Cuenca, Departamento de Cultura, 2002. 
antología mínima de este primer movimiento mexicano de vanguardia: con el título "Los directores del movimiento 'estridentista' en México". ${ }^{6}$ Ahí aparecen fragmentos de El movimiento estridentista de List Arzubide, "la risa de List Arzubide" de Arqueles Vela y los poemas "Puerto" y "Canción desde un aeroplano" de Manuel Maples Arce.?

Pero sin lugar a dudas, al menos seis años antes, para finales de 1921, existía ya un vínculo entre estos literatos de filiación próxima, o al menos un cierto conocimiento de alguno de ellos por parte de Manuel Maples Arce, fundador del movimiento estridentista: entre las más de doscientas firmas que suscriben (apócrifamente) el primer manifiesto - Actual No. 1. Comprimido estridentista de Manuel Maples Arce, hoja mural aparecida en la Ciudad de México en diciembre de 1921 - consta la de Hugo Mayo, único ecuatoriano incluido en este amplio directorio de la vanguardia internacional.

\section{"Buscábamos México y su Revolución"}

Invitado especialmente a colaborar en el número cien de la revista mexicana Cuadernos Americanos, Benjamín Carrión publica un texto entrañable: "Mis bodas de plata con México (1933-1958)", donde vuelve explícito lo que parece un tópico latinoamericano en los años treinta: el

6 Savia, núm. 42. Guayaquil, 17 de marzo, 1928, p. 8, en mi conteo. En el "Bazar de arte nuevo", ibid., p. 27, en mi conteo están el segundo poema de Maples Arce y el único de Ronzón Rivera. Esto es, siete meses antes de la carta de Palacio.

7 Algunas otras menciones al mismo movimiento se hacen durante esos años en Savia, editorial del Estado de Veracruz de cuyos talleres salía Horizonte, la revista que piloteaba Listz [sic] Arzubide, se ha suspendido por el momento. Oigamos lo que Magda Portal escribe sobre dicha editorial: "Contingencias de la política-coatismos [sic] de un régimen estatal en formación han suspendido la obra cultural del Estado de Veracruz, después de haber rayado en el mapa de las posibilidades, un camino luminoso a seguir por esta fuerte optimista nueva generación mexicana".

Dentro de estas notas del "Periscopio Literario" se comenta también que pronto aparecerá "Estridentópolis", libro de poemas de Mario Ronzón Rivera. Savia, núm. 39, 4 de enero, 1928, p. 23, en mi conteo. 
apasionamiento de una generación - la suya, nacida en el umbral del siglo XX - por la utopía de la transformación posible, encarnada en la recién consagrada Revolución mexicana, y, sobre todo, por su proyecto cultural:

Nuestra generación — días más, días menos, entre los siglos XIX y XXtuvo su niñez y su adolescencia encandiladas, deslumbradas por la imagen de México. Méjico, como nos corregía el profesor de castellano. Pero México, con X, una inmensa X para nosotros, que en ello encontrábamos fuerza y personalidad distinguidoras $[\ldots]$.

Buscábamos México y su Revolución. A México, realidad geográfica e histórica, lo íbamos encontrando día tras día [...] conjugado el impacto de la lectura con el sueño revolucionario que entonces vivíamos en casi toda América los hombres jóvenes y libres, estábamos dispuestos a pedirle a la Revolución Mexicana todos los avances, todas las purezas, todos los heroísmos. Pretendíamos que la Revolución Mexicana hubiera sido hecha y continuara viviendo, "a imagen y semejanza" de nuestros deseos, de nuestras prefiguraciones. Y, claro: en mucho nos satisfizo la realidad, pero en mucho también nos desilusionó. La culpa no era del proceso humano revolucionario únicamente: era de nuestra imaginación forjadora de Dulcineas[...]. ${ }^{8}$

Siendo todavía temprano para oler la desilusión, México asoma a finales de los años veinte y principio de los treinta para la inteligencia americana de avanzada ideológica como la encarnación de la utopía. La labor de las embajadas de México en Latinoamérica, cumplía para entonces un papel señero, representando un proceso y un camino posibles más que a sólo un país. Se fundaban "Sociedades de Amigos de México", se festejaba el 16 de septiembre en los países hermanos, y en el cuerpo diplomático aparecían en diferentes rumbos iberoamericanos, representantes de la talla cultural y política de Alfonso Reyes, José Rubén Romero, Moisés Sáenz, o Gilberto Owen.

8 Benjamín Carrión, "Mis bodas de plata con México (1933-1958)", Cuadernos Americanos, núm. 100, vol. C, año XVII, julio-octubre, 1958, pp. 77-79. 
Como emblema del afán de intercambio entre diplomáticos mexicanos y la inteligencia ecuatoriana, el ingeniero Raymundo E. Enríquez, enviado extraordinario y ministro plenipotenciario de México en Ecuador en 1936, impulsa la publicación de un volumen conmemorativo: el libro México, aparecido en Quito, conformado por páginas divulgadoras de la labor cultural de la Revolución mexicana leída desde Ecuador. En él aparecen textos de diversa autoría: de Pablo Palacio, Humberto Salvador, Aurora Estrada, Mary Corylé, Humberto Mata, Antonio Bellolio, Remigio Romero y Cordero, Francisco Huerta Rendón, Augusto Sacoto Arias, Jorge Pérez Concha; y Benjamín Carrión, este último hasta corto tiempo atrás, embajador plenipotenciario de Ecuador en México. La voluntad de hermanar a los dos países es más que manifiesta desde las palabras de introducción del tomo, que se avalan incluso en el posible origen "mexicano" de los caras, indios fundadores de la actual Quito (apoyado en fuentes orales, antiguas nacionales como el historiador Federico González Suárez, o modernas e internacionales como Max Uhle); o la etimología, que permitiría emparentar las lenguas tarasca y quichua. Pero sobre todo, la admiración del "hermano menor", Ecuador, por México, el hermano mayor y revolucionario. ${ }^{9}$

México y Ecuador: países hermanos de milenios quizá...

La rebeldía intelectual y artística del País del Norte asimilada perfectamente por la Nación del Sur. México y el Ecuador: hermanos por sus razas y más hermanos por su ideología.

A confirmarlo viene este Libro, en el que, el pensamiento ecuatoriano, conviviendo con el mexicano, nutriéndose de la maravillosa Obra Revolucionaria del País Orientador de América; expresa su sentir respecto de la Obra misma y de sus valientes gestores: en la frase de categórico sentido social, en la pulida dicción literaria, en la forma poemática de belleza

9 Como señalábamos al inicio, la imagen fraterna del segundo epígrafe de este artículo está expresamente también en Pablo Palacio: "México produce conscientemente la idea de un hermano mayor, más experimentado, que va triunfando en el arreglo de sus condiciones de vida y a quien queremos emular para poder vivir a su misma altura", Boletín trimestral. Comisión Ecuatoriana de Cooperación Intelectual, núm. I (1), Quito, Universidad Central, julio-septiembre, 1938, p. 53. 
lograda o de rebeldía siglo XX, en la charla plena de enseñanzas: diversas modalidades por las que México encárnase en el alma ecuatoriana.

Nos dicen, así mismo, de esta fuerte ligadura fraterna los Centros Ideológicos, Culturales y Artísticos, que, dentro del Ecuador, nacieron a la vida con nombres mexicanos, ellos son: Células Socialistas MÉXICO, en Quito y Cuenca; Sindicato de Escritores y Artistas MÉXICO, en Guayaquil; Grupo Artístico ERÉNDIRA, en Quito; Escuelas MÉXICO en Quito, Guayaquil, Riobamba, Ambato y Esmeraldas; Escuelas MOISÉS SÁENZ, en Pelileo. En México existen igualmente Centros Culturales y muchas avenidas con nombres ecuatorianos. ${ }^{10}$

La labor cotidiana de difusión en Ecuador resulta también parte de los agradecimientos expresos en dicha edición conmemorativa:

Para la enunciada Labor hemos contado con la gentileza del Gobierno ecuatoriano, al cedernos una hora quincenal, en la Estación Radiodifusora H.C.K. y el Teatro Sucre, para nuestras radiodifusiones y veladas de arte. También las estaciones H.C.J.B., "La Voz de los Andes", de Quito y las de "La Quinta Piedad" y "Ortiz" de Guayaquil, nos han favorecido con la concesión de algunas horas, y con su preciosa colaboración, altos valores intelectuales y artísticos de la República.

Ecuatorianos, aquí tenéis la Obra: el Libro MÉXICO es vuestro y nuestro; Libro de las dos Naciones, hoy más que nunca hermanas. ${ }^{11}$

La boga del México revolucionario alcanza otros niveles, de configuración institucional. Vale la pena comentar el acta de constitución del Instituto Ecuatoriano-Mexicano de Cultura, reunido en Quito el 25 de julio de 1938, por convocatoria del rector de la Universidad Central, Dr. Gualberto Arcos y del encargado de negocios mexicano, Óscar Cresdo de la Serna. ${ }^{12}$ Entre los reunidos se encuentran Jorge Fernández, Jorge Reyes, Nela Martínez; y destaca la organización del Instituto en diez secretariados, que citamos completa:

${ }^{10}$ México, Quito, Editorial Gutenberg-Bustamante y Compañía, 1936, p. 9.

11 Ibid., pp. 9-10.

${ }^{12}$ El acta consta en el ya mencionado Boletín trimestral. Comisión Ecuatoriana de Cooperación Intelectual, núm. I (1), Quito, Universidad Central, julio-septiembre, 1938, pp. 41-44. 


\section{Organización del Secretariado}

Secretario General, Dr. Pablo Palacio.

Secretario de Organización y Administración, Dr. Manuel Agustín Aguirre. Secretario de Asuntos Económicos, Sr. Humberto Mata Martínez.

Secretario de Asuntos Técnico-Profesionales, Dr. Ricardo Paredes.

Secretario de Propaganda y Prensa, Sr. Alejandro Carrión.

Secretario de Asuntos Científicos, Dr. Julio Arauz.

Secretario de Asuntos Educacionales, Dr. Emilio Uzcátegui.

Secretario de Cuestiones Artísticas y Literarias, Sr. Demetrio Aguilera Malta. Secretario de Cuestiones Sociales, Sr. Gustavo Valencia.

Secretario de Cuestiones Indigenistas, Dr. Humberto García Ortiz. ${ }^{13}$

En el discurso del rector universitario consta aún el halo de México como paradigma revolucionario: "En el transcurso de la historia sólo las páginas escritas con sangre han edificado. México ha sido pródigo en sangre y pródigo en ideales". ${ }^{14}$

Más radical, aunque menos épica, es la postura del flamante secretario general, el escritor Pablo Palacio:

México es hoy un laboratorio de justicia social en América; es un país situado políticamente, que ha definido el sentido de su vida y que definiéndolo ha encauzado hacia un solo punto convergente todas las fuerzas básicas del país: hacia el socialismo.

Toda su acción, en la división general de sus actividades materiales e intelectuales, está encaminada a eso. Para poner un solo ejemplo recordemos [en] el arte pictórico a Rivera y Orozco. Especialmente Rivera escribió en imágenes la historia de la opresión de la burguesía política y el levantamiento invencible de los indígenas y obreros mexicanos.

Con un país como éste no cabe cooperación intelectual neutral, nebulosa, indefinida, sin una definitiva decisión sobre lo que quiere e intenta esa cooperación.

${ }^{13}$ Ibid., p. 44. Se trata de intelectuales de izquierda del Ecuador, pueden distinguirse entre ellos liberales, socialistas, y comunistas.

14 "Discurso del Dr. Gualberto Arcos, Presidente de la Comisión Ecuatoriana de Cooperación Intelectual y Rector de la Universidad Central”, ibid., p. 47. 
Desentrañando intuitivamente la realidad mexicana, tres grandes conquistas encontramos dentro de ella: [reforma agraria, afirmación del nacionalismo mexicano, y reconocimiento de que el hombre es un fin social].

Éstas son las tres grandes bases sobre las que podemos cooperar intelectualmente: destrucción de la feudalidad: construcción de la solidaridad económica y social; afirmación del nacionalismo racionalista [...]; y reconocimiento de que el hombre, su progreso y su respeto son el único fin de la acción social.

Porque el espíritu de México es un laboratorio de todos estos grandes principios es porque estamos felices de buscar una definida cooperación intelectual. ${ }^{15}$

\section{Los TeXtos: Cuentos Indígenas, Viajes A MéXico}

El 9 de mayo de 1932, desde Guayaquil, el narrador ecuatoriano José de la Cuadra escribe al bibliógrafo hondureño radicado en México Rafael Heliodoro Valle:

Quiero rogarle un nuevo servicio. Estoy escribiendo ahora cuentos regionales ecuatorianos: indios, montuvios. Tienen las narraciones hueso de lucha social, pero la carne es fácil de digerir por cualquier estómago plácido y delicado. Desearía colaborar con ellos en revistas o periódicos mexicanos. Si pagan, bien. Si no pagan, también. Ojalá usted me ayudara un poco en esto. Una recomendación bastaría, que luego escribiría directamente yo a las redacciones. ${ }^{16}$

15 "Discurso del Dr. Pablo Palacio, secretario general del Instituto Ecuatoriano-Mexicano de Cultura", ibid., pp. 54-57. Llama la atención que quien hacia 1928 fuera estigmatizado por su poca fe en la presencia de lo social en el arte según el portavoz de la izquierda ecuatoriana, Joaquín Gallegos Lara, sea quien destaque de modo tan consciente el programa estético-político de Rivera como muestra por el interés en el Estado revolucionario mexicano como paradigma del socialismo. Al parecer la polémica de 1932 a 1934 sobre el papel del artista, presentó desde ese entonces más matices de los evidentes.

${ }^{16}$ La información de este capítulo se toma del epistolario de la Cuadra-Valle, que se encuentra en la Colección Rafael Heliodoro Valle del Fondo Reservado de la Biblioteca Nacional de México. 
El 6 de junio del mismo año, Valle le contesta desde su casa de Tacubaya, en la Ciudad de México, favorablemente, prometiéndole que Revista de Revistas (Semanario cultural del Diario Excélsior) publicará sus textos, aunque no los pagará pues no es parte de su política editorial. Le pide además ceñirse a un formato: de tres a cuatro páginas a máquina, "con un espacio". El 23 de junio, de la Cuadra le envía "un cuento de tema indio".

Rafael Heliodoro Valle, hombre de letras nacido en Tegucigalpa en 1891, desarrolló la mayor parte de su carrera intelectual - de al menos medio siglo - en México. Amigo lo mismo de autores románticos, modernistas y posmodernistas como Juan de Dios Peza, José Juan Tablada, Ramón López Velarde y Alfonso Reyes, que de los vanguardistas Carlos Noriega Hope y Manuel Maples Arce, su función de divulgador y puente entre varias generaciones literarias resulta también meritoria. Por su generosidad, compromiso latinoamericanista y por la importancia de sus relaciones, resultaba un contacto invaluable de aquel entonces para abrir caminos en México y Centroamérica a los noveles escritores hispanoamericanos.

José de la Cuadra, considerado a la fecha por la crítica ecuatoriana como el mayor cuentista moderno del Ecuador, es uno de los cinco integrantes del denominado "grupo de Guayaquil", conjunto de narradores socialrealistas nacidos en dicha ciudad de la costa ecuatoriana.

Según nuestro rastreo, se trata del envío de "Merienda de perro", que aparece menos de dos meses después, el 14 de agosto de 1932, en Revista de Revistas, en México. El texto en cuestión es presentado con la siguiente nota, bajo la foto del autor: "El distinguido hombre de letras ecuatoriano, doctor José de la Cuadra, autor de este cuento de primer orden — de su próximo libro Horno - que desde Guayaquil envía a Revista de Revistas". ${ }^{17}$

17 José de la Cuadra, "Merienda de perro", Revista de Revistas, año 22, núm. 1161, México, 14 de agosto, 1932, p. 12.

Para poder dimensionar lo estrecho del contacto de Valle con el Ecuador de los años treinta, valga mencionar, por ejemplo, que en 1932 aparece en la periférica revista hontanar de Loja — publicación colegial del grupo a.l.b.a. — un poema del hondureño. 
En contraste con los libros publicados por José de la Cuadra hasta entonces, al parecer la poética montuvia — propia del entorno costeño del agro ecuatoriano - apenas se definía como constante temática y estética del autor. Para esos años de profusa publicación, ${ }^{18}$ encontramos su firma en narraciones que oscilan entre un romanticismo tardío a mediados de los años veinte (cfr. "Olga Catalina", 1925; "La burla", 1926), un posmodernismo rural (por ejemplo, el cuento dedicado a Valle: "El maestro de escuela", 1929) y un indigenismo de corte de realismo social, a principio de los treinta (a los que siguieron "Chichería", "Merienda de

Después de la firma, el polígrafo y bibliógrafo centroamericano inserta la datación: "México, D.F., 1932". Se trata de "El unísono amor", que dará nombre a un libro de versos del autor, ocho años más tarde. [Cfr. Rafael Heliodoro Valle, "El unísono amor", hontanar, núm. II (10), diciembre de 1932, pp. 111 - 112]. Para entonces, Valle se encontraba perfectamente asentado, social y laboralmente, en México: llevaba once años de regreso en su segunda patria, después de haber servido en misión diplomática a Honduras como cónsul, primero ante la representación de Mobile, Alabama y luego ante la de Belice.

La presencia de este dato aislado - inclusión de un poema totalmente posmodernista en una revista de "el último rincón del mundo" a principios de los treinta— bien poco indicaría sobre la importancia del nombre de este intelectual en relación con nuestro país. Pero leído desde la perspectiva de su posterior calidad de miembro de la Academia Ecuatoriana de Historia y del Centro de Estudios Históricos de Guayaquil, así como de acreedor a la Orden al Mérito de Ecuador; además de mantener correspondencia entre finales de los años veinte y bien entrados los cincuenta con personalidades nacionales como Alfredo Pareja Diezcanseco, José de la Cuadra, Benjamín y Alejandro Carrión, Gerardo Gallegos, Colón Eloy Alfaro y Aurora Estrada Ayala, por ejemplo, y con instituciones tan distantes como la revista Proteo y la revista Savia (publicaciones guayaquileñas modernista y vanguardista, respectivamente), o la misma revista hontanar; avalan una continua y estrecha relación con la literatura y la historia ecuatorianas.

La mayor parte de los datos sobre R. H. Valle se han extraído de su Curriculum vitae, Tegucigalpa, Talleres Tipo-litográficos “Ariston” [1949].

Cfr., respecto a la relación de Valle con México, Yanna Hadatty Mora, "José de la Cuadra y Rafael Heliodoro Valle: cartas hispanoamericanas" (2004) y "Benjamín Carrión y Rafael Heliodoro Valle: una amistad mexicana" (2005).

18 "De la Cuadra es, acaso, el más prolífico de los escritores", dice la reseña y traducción de Panorama, revista de la Pan American Union, titulada "Escritores y poetas ecuatorianos vuelven a los temas sociales". Tomamos la cita de su reproducción en Mensaje de la Biblioteca Nacional, Quito, 1936, p. 57. 
perro", "Ayoras falsas"; el primero de El amor que dormía, 1930; y los tres últimos de Horno, 1932), pasando por alguna historia de voluntad moderna y vanguardista (así leemos el inicio de "Chichería", construido como poema visual; o la sorprendente construcción fragmentaria de "Malos recuerdos", en un libro por lo demás poco vanguardista, el mismo Horno). Con timidez asoman eventualmente el personaje y el entorno montuvios en esta etapa (quizá solamente "Olor de cacao" y "Colimes jótel", en Horno); vertiente que se privilegia y centraliza con esplendor en las páginas de "La Tigra", del mismo libro; y que encontraría su consagración apenas dos años después, en 1934, con su obra Los Sangurimas. Novela montuvia.

La primera mitad de la década del treinta acusa en el Ecuador - como en varios otros países iberoamericanos - la marca del derroque progresivo de una vanguardia apenas coronada a finales de los veinte, en lo explícito de proclamas y manifiestos; suplantada progresivamente en lo literario por una escritura más comprometida en la renovación política que en la renovación estética. Para 1932, la revista hontanar reproduce el artículo "Vanguardismo y comunismo en literatura" del ideólogo de la llamada generación del 30, Joaquín Gallegos Lara, otro integrante del mencionado Grupo de Guayaquil. ${ }^{19}$ En él se incluyen afirmaciones tan rotundas como "El vanguardismo literario, en Europa como en América, es únicamente la más a la moda de las escuelas de arte burgués en disputa". ${ }^{20}$

19 Respecto a la polémica Gallegos-Palacio, que pone en el centro la escisión entre las posibilidades estéticas de realismo social y vanguardia en el discurso ecuatoriano hacia 1932, cfr. María del Carmen Fernández, "Controversia Realismo abierto-Realismo social" en su minucioso estudio El realismo abierto de Pablo Palacio en la encrucijada de los 30, Quito, Ediciones Libri-Mundi, 1991.

20 Joaquín Gallegos Lara, "Vanguardismo y comunismo en literatura", hontanar, núm. II (10), diciembre, 1932, p. 91. Cfr. Es decisivo en esta revisión el esfuerzo antológico y crítico de Humberto Robles, La noción de vanguardia en el Ecuador. Recepción-trayectoria-documentos. 1918-1934, Guayaquil, Casa de la Cultura del Ecuador, 1989, p. 64. 
Así, en casi cualquier comentario de época, emergen

paradigmáticamente las tensiones existentes en el Ecuador de los años 1930-1934 entre la vanguardia formal, en sus diversas orientaciones - creacionista, ultraísta, psicoanalítica, nativista o socialista - y la vanguardia social, como consecuencia de un lento proceso de decantación literaria -en la que los acontecimientos político-económicos juegan un papel determinante que se inicia hacia 1927 y culmina en 1934 con el triunfo definitivo del realismo social. ${ }^{21}$

Paradójicamente, también es ése el lustro de publicación de la obra más vanguardista de los escritores ecuatorianos asociados con esta ruptura, que aparece a principios de los años treinta Vida del ahorcado de Pablo Palacio (1932), Boletines de mar y tierra de Jorge Carrera Andrade (1930), Hélices de huracán y de sol de Gonzalo Escudero (1933); así como En la ciudad he perdido una novela y Taza de té de Humberto Salvador (1930 y 1932, respectivamente).

Este comentario no tendría sentido, si no recordáramos que para 1930 ya estaba constituido el "núcleo montuvio" del Grupo de Guayaquil, a partir de Demetrio Aguilera Malta, Enrique Gil Gilbert y Joaquín Gallegos Lara, y la edición de su libro de narraciones Los que se van. Cuentos del cholo y del montuvio. El gesto de opción por un sujeto propio de la costa del Ecuador, portador de un imaginario, un lenguaje y una idiosincracia particulares, será una afirmación narrativa que apenas se empieza a insinuar como definitiva en José de la Cuadra para principios de los treinta. ${ }^{22}$

${ }^{21}$ Antonio Lorente Medina, "Barro de la sierra y las tensiones de la modernidad en el Ecuador de los 30", en Carmen Ruiz Barrionuevo y César Real Ramos, La modernidad literaria en España e Hispanoamérica. Actas del I Simposio Internacional de la Modernidad Literaria, Salamanca, Universidad de Salamanca, 1995, p. 93.

22 Como marca de época, con un poema de tema montuvio se convoca al premio de poesía de la revista Savia, concedido a las plumas nada realistas de Hugo Mayo y Tatá, en 1927. 
En esa carta, la frase escrita por de la Cuadra a Valle para ofrecerle su reciente producción narrativa parece atributo indistinto de este narrar "en nacional": cuentos regionales ecuatorianos. Y el texto que envía a México no parece considerar la cuota de la diferencia específica -el personaje montuvio - sino la esencia común a ambos, el indio, ${ }^{23}$ sujeto de enorme emergencia en México a partir de la Revolución de 1910. La definición y aun la decisión de escribir en esta nueva etapa narraciones de esqueleto duro de roer ("hueso de lucha social") y blanda musculatura ("carne fácil de digerir por cualquier estómago plácido y delicado"), suena, al menos dicho así, un tanto concesiva, o al menos, signada por una voluntad consciente de agradar y de captar un público mayoritario; quizá el imaginario de "lo que podría agradar en México". Pero resulta un parámetro de publicación quizá bastante adecuado, si se piensa en el perfil de la publicación en que aparece el cuento, por acción de Valle.

Revista de revistas, semanario del diario Excélsior, es una publicación familiar y "burguesa", dirigida justamente a lectores "de estómago plácido y delicado" (aún con lo alejado que resulta, strictu sensu, este cuento de crudo realismo frente al gusto de la revista de fin de semana). En sus páginas se incluye, junto a la nota social, la columna de grafología, la nota de la moda en Europa, y algún tema cultural tratado con mediana superficialidad.

Resulta de cierta exigencia y de avanzada que aparezca en ella un cuento tan crudo como "Merienda de perro". En él, José Tupinamba, un pastor indígena, descuida una noche de luna a sus hijos pequeños por rescatar a una oveja olvidada - ante el temor al látigo, al trabajo en las minas o al destierro; denunciándose el carácter de explotación feudal

${ }^{23}$ Ya en esos mismos años aparecen duras críticas al privilegio de la iconografía indígena como marcadora de la identidad estética de época. Salvador Novo dice en su relato Return Ticket (1928): "Voy viendo, Hawaii, que no me asombras mucho con tus productos. Tampoco me extrañarás con tus mujeres si todas ellas son como tus postales lo dicen: exactos duplicados de las sufridas criadas de mi casa y de las oaxaqueñas que tan en boga ha puesto el programa educativo de redención del indio y la escarlatina mural de Diego Rivera”. Salvador Novo, Return Ticket, México, Cvltvra, 1928, p. 102. 
en que viven los personajes serranos, explicitándose incluso el derecho de pernada ejercido sobre la cónyuge ausente, la Chasca, por parte del latifundista - con la lamentable consecuencia de la muerte de la niña de brazos, devorada por el perro ovejero. No se ahorran al lector detalles del realismo maniqueo, abundancia de exclamaciones explícitas, o la pintura de la grandiosidad de la naturaleza frente a la sordidez de la condición humana: "La soberana belleza de esa noche, que hablaba mil lenguas, no hablaba acaso el humilde quechua - mezclado de español y de dialectos - de José Tupinamba".

Más allá de la crítica a la que se presta enarbolar de manera icónica al sujeto indígena, el tema de la educación integradora del indio en el plan de la nación revolucionaria mexicana es un asunto al que se adhieren con fervor los pensadores de avanzada ecuatorianos. Hace falta, sin duda, un artículo que comente, históricamente, el significado que México representaba como modelo educativo en todos los niveles para Ecuador en esos años; con una mención especial al viaje de Fernando Chaves a México, y la acción en Sudamérica del educador rural mexicano Moisés Sáenz, que llegara a ser subsecretario de Educación en el gobierno de Plutarco Elías Calles. Ya en estos senderos, es imposible evitar la referencia a una invitación oficial dentro del rico epistolario de Valle: "Moisés Sáenz saluda atentamente a su estimado amigo el señor Rafael Heliodoro Valle, y se complace en invitarlo a la cena que se servirá en el Hotel Plaza, el jueves 19 del actual; a las 19.30 en honor de Fernando Chaves, maestro ecuatoriano y escritor que está en México por invitación de la Secretaría de Educación Pública”. Muy interesante resulta también la narración autobiográfica de Fernando Chaves, educador y narrador ecuatoriano, Crónicas de mi viaje a México. 1934-1935. A éste le llaman la atención las movilizaciones en el imaginario social que ha implicado la Revolución mexicana; por ejemplo, glosa la figura de un político mexicano, en un recuento en torno a la idea del mestizaje:

Lleva orgullosamente - por lo demás como casi todos los hombres de figuración política, literaria, científica, militar- su porcentaje subido 
de sangre india. Acaso por ello México ha entrado en la historia actual con un firme paso de avance. El que sus hombres dirigentes no tengan ese encogido gesto de ocultación cuando se habla de su origen indio más o menos próximo, ha producido la atención fervorosa que el político mexicano entrega a los problemas del pueblo.

Esto no sucede en las otras naciones en que la proporción de la raza cobriza es alta, preponderante. En ellas, el político que lleva gotas de sangre indígena en las venas las está constantemente disimulando, pidiendo perdón por ellas [...] México está en camino de resolver sus angustiosos problemas biológicos, educativos, de transporte, y de habitación por que sus políticos mestizos han superado este triste período de vergüenza de ser mestizos en que se encuentran, todavía, por desgracia, los nuestros. Los mexicanos, sintiéndose orgullosos de ser mestizos, quieren resolver de la mejor manera posible los asuntos que atañen a los otros mestizos. ${ }^{24}$

Idealización, quizá, podríamos pensar hoy. Pero ocurre más la contraposición Ecuador-México cuando visita las escuelas rurales indígenas:

Ya nos estamos alejando. Me llevo planas y dibujos de los muchachos que al fin me cogieron confianza y que me los obsequian cuando les digo que vengo de muy lejos y que allá también hay "inditos" que aprenden y que les quieren y que son parecidos a ellos.

He mentido por no poder decir la verdad. Los "inditos" nuestros no aprenden todavía sino en muy pocos casos. Cuando el teniente político les presiona. Rara vez porque alguien los convence. Qué lejos está nuestra escuela del barrio indio y de la tierra nutricia. ${ }^{25}$

Muchos testimonios del movimiento artístico de época llaman la atención del curioso viajero: lo mismo nociones de fotografía, propor-

${ }^{24}$ Fernando Chaves, "Una tumba que encierra a un vivo", Crónicas de mi viaje a México, Quito, Banco Central del Ecuador, 1992, pp. 54-55. Mis cursivas marcan cómo textualmente al felices con que Palacio califica a los mexicanos, se correspondería este tristes, para definir a los ecuatorianos, pues el hermano menor aún no consolidaba su propia revolución.

${ }_{25}$ Ibid., "El pozo artesiano", p. 93. 
cionadas por Manuel Álvarez Bravo y admiradas en la obra de Edward Weston; que el cartelismo de propaganda, expuesto en Bellas Artes e impulsado por la Secretaría de Educación:

En México, aprendí, de maestros como Álvarez Bravo que se dignó conversar algunas veces para explicarme el porqué de sus fotos. Me obsequió el material de un álbum de fotografías de monumentos dispersos por la ancha tierra azteca. No las iglesias conocidas, sino unas pequeñinas, recatadas y como dormidas en la soledad de la campiña. [...] Álvarez me enseñó la perspectiva. ${ }^{26}$

De México se exhiben numerosos carteles. En ellos la tipografía ocupa el primer plano. El dibujo, escaso y de grandes trazos y reforzado con manchas de fuerte color, es de vigorosa sequedad y expresión. Nada de finuras ni medios tonos. La blandura está proscrita. Las artes de la reproducción gráfica han de recorrer algún camino antes de que estos carteles sean todo lo que quieren ser: estímulos del ojo y del cerebro. ${ }^{27}$

\section{RISA DE RECIPIENTE, RISA DE POTRILLO}

Finalmente, del hallazgo de la carta del inicio y el contraste de personalidades y estéticas, seduce dejar en el aire una broma lanzada hace ya tres cuartos de siglo. Se acercan por asociación del referente dos elementos. Del destinatario de la carta aquí citada, queda la risa congelada por la máscara de Germán Cueto y la palabra de Arqueles Vela:

con su enorme risa de la edad de piedra, trituradora de todas las lágrimas[...] es una risa aumática, una risa de recipiente[...] Cuando se charla con List Arzubide, hay el peligro de que, algo de nuestra tristeza o de nuestra alegría, naufrague en el abismo de su carcajada", ("La risa de List Arzubide", prólogo a El movimiento estridentista).

Del remitente, la sonrisa y la risa, según la pluma memoriosa de Alejandro Carrión: "La sonrisa siempre en los labios delgados y en los

${ }^{26}$ Ibid., "El reino de la fotografía", pp. 225-226.

${ }^{27}$ Ibid., "Exposición de carteles", p. 276. 
ojillos de agudísimo mirar, burlones[...] Y, de pronto, el estallido de su risa de potrillo tierno, como él mismo la describiera" (Alejandro Carrión, en Pablo Palacio, Obras completas, 1964).

Risa del encuentro del proyecto epifánico, mesiánico, vuelto real, para los mexicanos, en esos años. Risa del alborozado contacto con quien lo encontró, modélica promesa, para los ecuatorianos. Si se nos permite nos quedamos con esto, en la imposible coronación del instante, como quería la vanguardia, del feliz encuentro metonímico, lautreamontiano, del recipiente y el potrillo, sobre una hoja de papel. 


\section{BIBLIOGRAFÍA}

BOLETÍN TRIMESTRAL, núm. I (1), Comisión Ecuatoriana de Cooperación Intelectual, Quito, Universidad Central, julio-septiembre, 1938.

CARrión, Benjamín, "Mis bodas de plata con México (1933-1958)", Cuadernos Americanos, núm. 100, vol. C, año XVII, julio-octubre, 1958 .

Chaves, Fernando, Crónicas de mi viaje a México. 1934-1935, Quito, Banco Central del Ecuador, 1992 (Col. Los cuadernos del caminante, II).

Fell, Claude, José Vasconcelos. Los años del águila (1920-1925). Educación, cultura e iberoamericanismo en el México post-revolucionario, México, UNAM, 1989.

FERnÁNDEZ, MARÍA Del CARMEN, El realismo abierto de Pablo Palacio en la encrucijada de los treinta, Quito, Libri Mundi, 1991.

HADATTY MORA, YANNA, "José de la Cuadra y Rafael Heliodoro Valle: cartas hispanoamericanas", Kipus. Revista andina de letras, núm. 16 Quito, Universidad Andina Simón Bolívar, 2003, pp. 73-87.

"Benjamín Carrión y Rafael Heliodoro Valle: una amistad mexicana", Re/incidencias. Anuario del Centro Cultural Benjamín Carrión, año IV, núm. 3, 2005 (en prensa).

List ARZUBIDE, GERMÁn, Opiniones sobre el libro "El movimiento estridentista", Jalapa [s/e], 1928.

Lorente Medina, ANTONiO, "Barro de la sierra y las tensiones de la modernidad en el Ecuador de los 30", en Carmen Ruiz Barrionuevo y César Real Ramos, La modernidad literaria en España e Hispanoamérica. Actas del I Simposio Internacional de la Modernidad Literaria, Salamanca, Universidad de Salamanca, 1995.

NiEMAYER, KATHARINA, "Arte-vida: ¿Ida y vuelta? El caso del estridentismo", en Naciendo el hombre nuevo...Fundir literatura, artes y vida como práctica de las vanguardias en el Mundo Ibérico, Frankfurt am Main, Vervuert/Iberoamericana, 1999. 
MÉXICO, Quito, Editorial Gutenberg- Bustamante y Compañía, 1936.

Novo, SAlvador, Return Ticket, México, Cvltvra, 1928.

PALACIO, PABlo, Débora (novela), Quito [s/e], 1927. Portada de Latorre. Exlibris de Kanela.

, Un hombre muerto a puntapiés (cuentos), Quito, Imprenta de la Universidad Central, 1927.

,Vida del ahorcado. Novela subjetiva, Quito, Talleres Nacionales, 1932.

REVISTA HÉLICE, introd. de Vladimiro Rivas Iturralde, Quito, Banco Central del Ecuador (Col. Revistas Ecuatorianas, LVIII).

Robles, Humberto, La noción de vanguardia en el Ecuador. Recepción-trayectoria-documentos. 1918-1934, Guayaquil, Casa de la Cultura Ecuatoriana, 1989.

SAVIA, REVISTA DE INFORMACIÓN, Arte i Letras, editada por Gerardo Gallegos y José Aspiazu Valdés, Guayaquil, 1925-1928.

SCHNEIDER, LUIS MARIO, El estridentismo o una literatura de la estrategia, México, CONACULTA, 1997 (Lecturas mexicanas, $4^{\mathrm{a}}$ serie).

Valle, Rafael Heliodoro, Curriculum Vitae, Tegucigalpa, Talleres Tipo-litográficos “Ariston” [1949].

Verdugo CÁRdenas, JaCKelín, Hugo Mayo y la vanguardia, Cuenca (Ecuador), Facultad de Filosofía, Letras y Ciencias de la Educación de la Universidad de Cuenca, Departamento de Cultura, 2002. 